\title{
ENTRE DIFERENÇAS E PRECONCEITOS: UM OLHAR PARA A IMIGRAÇÃO EM “GRINGA" DE MÁRCIA KUPSTAS
}

\author{
Paulo Fernando de Sousa Pereira ${ }^{1}$ \\ Yara das Chagas Furtado ${ }^{2}$ \\ Francisco Pereira Smith Júnior ${ }^{3}$
}

\begin{abstract}
RESUMO
Este artigo tem como objetivo fazer um estudo a partir do conto da autora Márcia Kupstas intitulado "Gringa", embasando-o nas obras teóricas de SAYAD (1998), ECO (2006), HALL (2006) entre outros que tratam sobre a migração, imigração e a literatura. Procura-se investigar as possíveis relações entre as obras para entendermos como acontece esse processo e ao mesmo tempo compreendermos como a sociedade receptora enxerga o imigrante diante das divergências e como que ela lida com aquele que vem de outros lugares, e qual é a visão do próprio imigrante em relação à nação que o recebe, a literatura como um produto social vem refletir esses fenômenos. Para isso, nossa análise contemplará a personagem principal da estória chamada Sorá, com o intuito de analisarmos como ela comporta-se diante do desconhecido e ao mesmo tempo se o que é diferente pode ser motivo de preconceito. Neste cenário de mudanças, apresentamos ideias centrais para entendermos como as relações e concepções são construídas, como o imigrante se vê em uma perspectiva de pertencimento neste processo, numa série de discursos, apresentando-se sob diversas formulações no processo de domínio do espaço, memórias, e como é vista ou construída a cultura do outro, e se esses fatores contribuem para sua aceitação de cunho social.
\end{abstract}

Palavras-chaves: Imigração. Literatura. Sociedade. Preconceito.

\begin{abstract}
This article aims to make a study based on the tale of the author Márcia Kupstas entitled "Gringa", based on the theoretical works of SAYAD (1998), ECO (2006), HALL (2006) among others dealing with migration, immigration and literature. We try to investigate the possible relations between the works to understand how this process happens and at the same time to understand how the receiving society sees the immigrant in the face of divergences and how it deals with the one who comes from other places, and what is the vision of the own immigrant in relation to the nation that receives it, literature as a social product comes to reflect these phenomena. For this, our analysis will contemplate the main character of the story called Sorá, with the purpose of analyzing how it behaves in the face of the unknown and at the same time if what is different can be cause for prejudice. In this scenario of changes, we present central ideas to understand how relationships and conceptions are constructed, how the immigrant sees himself in a perspective of belonging in this process, in a series of discourses, appearing under diverse formulations in the process of domain of space, memories, and how the culture of the other is viewed or constructed, and whether these factors contribute to its social acceptance.
\end{abstract}

Key-words: Immigration. Literature. Society. Prejudice.

\footnotetext{
${ }^{1}$ Mestrando do Programa de Pós-Graduação em Linguagens e Saberes na Amazônia (PPLSA) - Universidade Federal do Pará - Campus Bragança. E-mail: jave7jave@yahoo.com.br

${ }^{2}$ Mestranda do Programa de Pós-Graduação em Linguagens e Saberes na Amazônia (PPLSA) - Universidade Federal do Pará - Campus Bragança. E-mail: yarafurmestranda@gmaill.com

${ }^{3}$ Professor Adjunto III da Universidade Federal do Pará. Vice-Coordenador do Programa de Pós-Graduação em Linguagens e Saberes na Amazônia da Universidade Federal do Pará/Campus Bragança. E-mail: fsmith@ufpa.br
} 


\section{INTRODUÇÃO}

Este trabalho faz uma análise no conto "Gringa" de Márcia Kupstas com o objetivo de estudar a imigração e como a sociedade receptora enxerga o imigrante. Para isso observaremos a partir das diferenças como que os preconceitos se constituem, pois quando falamos de culturas diferentes, já temos uma noção que de alguma forma chegará o momento em que entrarão em conflitos e no caso do imigrante esse confronto é bem maior, já que o ele é visto como alguém que não é aceito, se sentindo rejeitado ou mesmo um intruso.

Essa realidade será bem representada pela personagem Sorá que carrega em seu psíquico esse peso cultural e preconceituoso que enfrentou em seu país de origem, o Brasil, que desde criança já sofria por essa resistência pela cor da sua pele negra, e que no conto irá retratar como se sente num país estrangeiro e a forma como foi recebida entre pessoas de cor de pele bem diferente e, além disso, de cultura muito mais diferenciada.

Para Eco (2006, p. 107) “imigração” é quando alguns indivíduos (...) transferem-se de um país ao outro (...)", é algo mais formal, planejado e controlado que se faz conforme as necessidades que estão a existir no país.

Apesar de termos a noção que o imigrante é alguém que está legalmente no país, este não é bem aceito, por que não pertence ao local, não traz consigo a ideia de pertencer, não comunga dos mesmos direitos de quem é da terra.

Por esse motivo o trabalho vem abordando muitos fatores que originaram-se do resultado da imigração através dos tempos, imigrações forçadas como a escravista, imigrações em massa em busca de sobrevivência, imigração por contratos trabalhistas, imigrações para branqueamento, entre outras, mas também mostra um preconceito e resistência de algumas sociedades, que seguem padrões estereotipados, por outro lado países que se renderam às novidades de novas culturas acabam se desenvolvendo mais que os outros em muitos aspectos, seja econômico, político, e culturais.

Outro conceito que será apresentado é o multiculturalismo que problematiza essas questões culturais e políticas entre as sociedades, que gera outro conceito como o hibridismo, que alguns autores como Cozer (2005) e Burke (2003) definem que somos sujeitos híbridos, que não existe nada puro, somos resultados de uma miscigenação de muitos contatos entre etnias de diferentes povos, construindo uma identidade híbrida.

O trabalho faz uma relação interdisciplinar entre a migração e a literatura, como forma de aproximar as diferentes ciências para a compreensão de fatores sociais que são presentes e atuais, demonstrando assim que o conhecimento não está fragmentado, mas sim relacionado. 
É uma incursão pelo mundo literário tendo como base o conto "Gringa" de Márcia Kupstas e os conceitos apresentados pelos estudos da migração.

\section{IMIGRAÇÃO E IMIGRANTE}

Quando se fala em imigração é necessário termos em mente que este conceito abrange um grande número de pessoas, mas o que é imigração e por que essa definição? Para Sayad (1998, p. 15) “a imigração é, em primeiro lugar, um deslocamento de pessoas no espaço, e antes de mais nada no espaço físico", ou seja, é definido como um deslocar de pessoas de um local ao outro, então imigrar é algo que está condicionado a todo ser humano, já que estamos indo constantemente de um lugar ao outro, então somos imigrantes por natureza ou a natureza é que nos faz ser imigrantes? É uma questão que precisamos pensar e conceituar para nossa melhor compreensão.

O imigrante é aquele que de uma forma ou outra participa da "ilusão" da imigração, pois ao mesmo tempo em que são considerados como um povo em um estado provisório, ao mesmo tempo são considerados como definitivo, porém sem ter uma declaração oficial de sua cidadania oficial. Então ser imigrante está ligado a uma necessidade do momento, que pode ser vista como de interesse econômico, principalmente, mas não sendo somente esta a característica que faz um imigrante.

Ser ou definir o que seja um imigrante é perceber como este lida a partir das relações com a sociedade, pois para Ianni (2004, p. 93) “o migrante pode ser visto como aquele que foge e busca, é tangido e extravia-se, ambiciona e frustra-se, resigna-se e realiza-se" e estão em busca de um espaço para poder se instalar, este autor explica também no mesmo parágrafo que "são muitos os que se perdem na viagem, ficam pelo caminho, regressam e retornam" (IANNI, 2004, p. 93).

A realidade de um imigrante é em nossa atualidade uma questão ainda não resolvida e cada vez mais as nações estão se tornando em diferentes aspectos mais fechadas, principalmente, quando envolve o econômico, pois os nativos de maneira alguma querem perder seus postos de trabalho para um imigrante, já que estes são movidos pelo econômico em busca de melhores condições para o sustento de suas famílias.

Mas a frustração é a principal marca de um imigrante, sendo que ele sempre vai em busca de algo melhor e alguns casos isso acaba se tornando um grande problema, porque há o aproveitamento por alguns como mão de obra barata, ou seja, o imigrante é definido, 
principalmente, pelo mercado, capaz de fazer coisas que os nativos não fazem, como forma de ter naquela nação algo para fazer.

Os imigrantes são em grandes números refugiados devido às grandes guerras civis que acontecem em suas terras de origem, assim como as crises que geram um grande fluxo de pessoas em direção a outros locais como forma de fuga da fome. Mas o que é mais percebido quando se fala de imigração e de imigrante é a cultura que entra em choque e a nacionalidade acaba falando mais alto.

\section{IMIGRAÇÃO E IDENTIDADE}

Falar de identidade é entrar em universo de demarcação de lugares, de caracterização dos seres e das coisas. E compreender no mundo atual essa questão não é tão simples quanto se imagina, já que os grupos, as pessoas, as sociedades apresentam diferenças que muitas vezes não pode ser definida como uma identidade plural.

A identidade passou por algumas transformações ao longo do tempo, ou seja, ela segue uma forma que é determinada pela época em questão, então falar de identidade não é só um ponto de identificação, mas é algo que está ligado a um processo histórico.

\footnotetext{
A questão da identidade está sendo extensamente discutida na teoria social. Em essência, o argumento é o seguinte: as velhas identidades, que por tanto tempo estabilizaram o mundo social; estão em declínio, fazendo surgir novas identidades e fragmentando o indivíduo moderno, até aqui visto como um sujeito unificado. A assim chamada "crise de identidade" é vista como parte de um processo mais amplo de mudança, que está deslocando as estruturas e processos centrais das sociedades modernas e abalando os quadros de referência que davam aos indivíduos uma ancoragem estável no mundo social (HALL, 2006, p. 7).
}

O que percebemos é que a identidade não é algo mais unificado, identificado como apenas uma característica que marca uma determinada comunidade, povo ou grupo, mas o que vemos na atualidade pós-moderna é uma fragmentação. Para Hall (2006, p. 10) existem ou existiram três concepções de identidade, a primeira é definida como sujeito do iluminismo que "estava baseado numa concepção da pessoa humana como um indivíduo totalmente centrado, unificado, dotado das capacidades de razão".

A outra é o sujeito sociológico que discordava do sujeito do iluminismo, pois achava que o mundo moderno era muito complexo e que o núcleo interior do sujeito não era autônomo, mas constituído das relações com outros sujeitos que é responsável pela mediação das coisas e o último é o sujeito do pós-moderno "o sujeito, previamente vivido como tendo uma identidade unificada e estável, está se tornando fragmentado; composto não de uma 
única, mas de várias identidades, algumas vezes contraditórias e não-resolvidas" (HALL, 2006, p. 12).

Com essas concepções e a última como marca da pós-modernidade é essencial para compreendermos o processo de migração e percebermos que o mundo atual é resultado, principalmente, de um sujeito marcado por essas diferentes fragmentações, já que o processo de migração expõe as culturas um processo de misturas, ou seja, já não é dizer que existe uma características marcadamente de um povo, pois o contato entre os povos gerou essas marcas que sempre vão lembrar um outro de forma que as características sempre terão algo de um outro povo, ou seja, é a "pluralidade de centros de poder" (HALL, 2006, p. 16).

Quando falamos de imigração é entrar no campo de demarcação de identidade, já que este processo que envolve a humanidade desde que nos entendemos formou e forma as diferentes nações, assim como os povos.

Na sociedade pós-moderna essa fragmentação que é percebida tem a ver em parte por esse contato entre diferentes povos, porém não existe mais uma cultura, um povo, mas diferentes formas de pensar e de se entender enquanto ser humano, logo aquilo que me caracteriza é visto em perspectiva diferente do que oficialmente é registrado.

Não devemos esquecer que cada povo se caracteriza de uma forma, ou seja, tem a sua identidade. E esta visão gera a alteridade, ou seja, o respeito pelo o que o outro é em sua forma de pensar, de vestir e de se portar.

Isso não é levado em conta quando falamos do imigrante, pois é como se ele fizesse parte da nossa cultura e de nossa identidade, porém sem direito a ela. E não levamos em conta que está em nosso meio, porém a sua identidade já está formada por sua cultura e que ele apenas irá se adaptar, mas não necessariamente mudá-la.

\begin{abstract}
Se esquerda e direita partilham alguns aspectos com que abordam a imigração, é porque essa partilha assenta em bases mais fundas, nomeadamente no quadro nacional que determina não só a ação, como também a sua grelha de entendimento da política. Não há processo de produção de "alteridade", de estabelecimento de fronteiras entre um "nós" e um "eles" que seja, do ponto de vista político, inocente, i.e., que não seja constitutivo de uma diferença que arrasta consigo uma partilha desigual. O Estado-nação, enquanto máquina de produção e de gestão de identidades, produz um espaço de pertença que é, ao mesmo tempo um espaço de exclusão. E o imigrante é, em relação a esse espaço de pertença da nação, o "outro" nacional e o "outro racial", a figura por excelência do excluído (DIAS, 2012, p. 19).
\end{abstract}

Ou seja, não tem como produzirmos a alteridade sem produzirmos a exclusão e o imigrante sempre irá ser visto como o intruso no contexto de pertença e de construção de uma identidade, pois as relações entre o "eu" e o "outro" são pensadas sempre a partir de uma mesma cultura e no caso de uma identidade. 


\title{
3. MULTICULTURALISMO, PLURICULTURALISMO E HIBRIDISMO
}

Quando falamos de identidade devemos observar como os nossos centros urbanos ou mesmo as periferias estão formadas por uma diferença muito grandes de povos e essas diferenças de povos e grupos acaba por formar uma diversidade de culturas o que leva o multiculturalismo a ser estudado sob algumas óticas, conforme discorre Neto (2005, p. 289):

\begin{abstract}
A diversidade demográfica e cultural das sociedades humanas, mais precisamente quando se quer estudar a coexistência da diversidade sócio - cultural e a construção de identidades em um mesmo país ou em uma determinada região, a epistemologia multicultural, ao arguir a modernidade sobre a questão da diferença nas categorias filosóficas, política e social, ultrapassa as especificidades nacionais e inscreve-se como conceito civilizacional no discurso que as sociedades contemporâneas elaboram em contraposição às ideologias monoculturais.
\end{abstract}

Entre muitos questionamentos sobre os diversos traços físicos que a humanidade apresenta como a cor da pele, olhos, boca, nariz, entre outros aspectos bem marcantes, sem esquecer o de lugar de origem, também terão suas diferenças na história, na política, cultura, economia, geografia, na religião, e linguagem, etc.

Toda essa diversidade é chamada de "multiculturalismo" e "pluriculturalismo" porque uma está inserida na outra, pois o multiculturalismo vem reunir uma pluralidade de sentidos, problematiza questões complexas e contraditórias em curso na sociedade pós-industrial, que atuam como indicadores da crise do projeto de modernidade e descreve a existência de muitas culturas numa região, cidade ou país, com no mínimo uma predominante, o que antes era balizado pelo marco nacional, hoje foi substituído pelo regional, centralizando uma diversidade cultural local, vem criando etapas promovendo o surgimento de novas organizações políticas, religiosas e culturais, com o objetivo de organizar as diferenças, redimensionando as diversas fronteiras da diferença, reestruturando as identidades (NETO, 2005).

Vivemos num mundo globalizado e, infelizmente, a diversidade cultural é vista por alguns como uma ameaça para a identidade da nação, provocando em alguns o desprezo e indiferença, como ocorre no Canadá entre habitantes de língua francesa e os de língua inglesa, apesar do Canadá ser o primeiro país a adotar uma política multiculturalista, ganhando mais espaço, também em outras questões. Segundo Neto (2005, p. 291):

Já os grupos étnicos resultam de processos de imigração, tomando como critérios geográficos, étnicos ou religiosos, constituem comunidades relativamente 
homogêneas. A esses grupos, ainda segundo a análise de $\mathrm{Kymlicka}^{4}$, não se assegurariam direitos especiais, mas apenas o reconhecimento cultural e identitário.

Nesse processo observa-se que esse choque de contato entre os indivíduos resulta em novas realidades de cultura que define a construção do sujeito e de sua identidade, ocorrendo uma pluralidade cultural produzindo novas epistemologias e gerando conflitos desses sujeitos metropolitanos.

Aqui no Brasil, por muito tempo, acreditava-se que a diversidade que hoje somos originava-se apenas dos negros, brancos e índios, deixando de lado as influências de povos imigrantes, surgindo novas diversidades em todos os sentidos como elementos formadores de novas características físicas e identidades étnicas de acordo com cada região.

No Brasil temos uma grande variedade de misturas culturais, por ocasião dos encontros culturais frequentes por meio dos imigrantes, uma tendência para essa mistura e hibridização. No passado essa miscigenação não era aceita, o mestiço era visto como "sangue fraco", e sempre ficava à margem da sociedade, característica de uma sociedade que não tinha ainda um conhecimento sobre troca cultural e misturas de raças.

São poucos os países que são etnicamente homogêneos, mas não se pode generalizar que tais conceitos podem ser verdadeiros, que existam povos puros, pois a multiculturalidade traz justamente levantamentos de certos padrões acerca de comportamentos e culturas que possam estar ultrapassados, ao impor certas regras. Para alguns essa mistura ameaçou a unidade nacional, mas é preciso compreender que essas classes sociais sempre estão em processo de construção.

O que ocorre em algumas situações é o preconceito que é gerado pela discriminação pelo diferente, se omitindo a novas experiências.

Pode-se dizer que a razão de alguns países adotarem uma política multiculturalista deve-se, em grande parte, à dinâmica das migrações a às reivindicações por parte de grupos, cuja identidade emerge de ideologias ou costumes diferentes dos que são normatizados pela definição de uma identidade nacional construída pelo processo de homogeneização cultural-identitária característico do Estado-Nação, onde a monocultura e a identidade única são consideradas como norma social (NETO, 2005, p. 298).

O multiculturalismo só ganhou evidência quando foi tratado como fator político trazendo questões de resistências sociais, mostrando-os como fator de enriquecimento cultural. Dentro desta perspectiva, entra algo mais novo que é o conceito de hibridismo, que vem abordando questões sobre essa mistura de etnias, de culturas que são fatores positivos de

\footnotetext{
${ }^{4}$ KYMLICKA, Will. La citoyenneté multiculturelle: une théorie libérale Du droit dês minorités. Montréal, 2001.
} 
inovação, pois é um grande desafio interculturalidade. Segundo Cozer (2005) antes o hibridismo reportava à biologia e à preocupação com a mistura das espécies que aflorava em pesquisas e escritos europeus do século XIX, que a primeira definição de hibridismo veio no dicionário Houaiss da Língua Portuguesa com um conteúdo negativo, apontando para o cruzamento animal de espécies diferentes.

\begin{abstract}
Ao traçar paralelos com espécies híbridas de animais estéreis e plantas debilitadas, a ciência européia divulgou o princípio de que miscigenação seria danosa para a espécie humana. Cientistas enfatizaram que o cruzamento de raças diferentes resultaria não tanto em infertilidade, mas, principalmente, na decomposição ou degradação dos descendentes híbridos (COZER, 2005, p. 165).
\end{abstract}

No decorrer da história as mudanças ocasionadas com a mistura de raças, a carga de conflitos gerou o híbrido e com o tempo, o que antes havia sido desenvolvido pela biologia, os estudos linguísticos, tomaram emprestados para abordar as misturas entre uma língua européia e outra língua nativa ou africana que resultaram na língua crioula (COZER, 2005), até se solidificar. Para uma melhor visualização, vamos a um exemplo mais prático, quando escravos eram separados das suas famílias, indo para fazendas coloniais, as comunidades tinham várias línguas naturais e não tinham uma oportunidade de aprender formalmente a língua do colonizador, então desenvolviam um pidgin, isto é, um sistema linguístico rudimentar, com palavras baseadas na língua do colonizador, gerando outra língua.

Houve momentos de reações contra o estrangeirismo, surgindo até movimentos de purificação, só que o tempo se encarregou de expandir tais elementos descendentes da globalização, muito próprio de cada região. Mas o conceito de hibridismo é muito mais amplo, Peter Burke (2013), diz que não existe uma fronteira cultural nítida entre grupos, e sim, pelo contrário, um continuum cultural. É um grande fenômeno analisado por este autor, que traz uma diversidade de território, e de globalização.

Exemplos de hibridismo cultural podem ser encontrados em toda parte, não apenas em todo o globo, como na maioria dos domínios da cultura, religiões sincréticas, filosofias ecléticas, línguas e culinárias mistas e estilos híbridos na arquitetura, na literatura ou na música. Seria insensato assumir que o termo hibridismo tenha exatamente o mesmo significado em todos estes casos (BURKE, 2003, p. 23).

Burke (2003) apresenta três tipos de hibridismo ou processos de hibridização, que envolvem artefatos, práticas, e povos. No artefato refere-se por exemplo a construções, como na Ucrânia do século XIV com arquitetos italianos, e também ortodoxos ao construírem uma igreja no século XVI. Artesãos alemães, italianos e armênios, contribuíram para a criação de um estilo hibrido, combinando elementos de tradições e culturas, com diferentes elementos. 
Outro tipo importante de artefato é o texto, e as traduções são os casos mais óbvios de textos híbridos, já que procuravam por aquilo que era conhecido com "sujeito equivalente", que envolvia a introdução de palavras e ideias que são familiares aos novos leitores, mas que poderiam não ser inteligíveis na cultura na qual o livro foi escrito.

As práticas híbridas, se identificam nas religiões, na linguagem, no esporte, e na música, que fornece um rico exemplo de prática de hibridização. O jazz sendo um exemplo famoso que mostra uma combinação de elementos, e se formos avaliar ainda, na nossa música brasileira existem muitas misturas, e a cada ano surgem músicas sempre trazendo uma "novidade", o reggae uma forma de música que originou na Jamaica e que agora já se encontra um pouco mais modificado.

O terceiro caso é os povos híbridos, que é o mais importante nesse processo, temos grupos como os anglo-irlandeses, os anglo-indianos, e os afro-americanos, por serem de culturas diferentes, os filhos nasceram dessa mistura, dando origem a indivíduos híbridos.

Burke (2003) ainda destaca que as metrópoles são um local de grandes trocas de culturas, cruzamentos tanto de comércio quanto de cultura com a presença de diferentes grupos de imigrantes. Outro local também de grande contatos são os portos como Veneza do século XV, a Lisboa e a Sevilha do século XVI, e outro caso de hibridismo também são as fronteiras, esses locais de encontros são onde mais acontecem as trocas culturais, entre modas, língua, que acaba refletindo na interação, nos contatos étnicos, e no desenvolvimento, construindo a identidade do indivíduo e na identidade regional.

\section{ENTRE AS DIFERENÇAS E OS PRECONCEITOS}

Márcia Kupstas é professora e escritora descendente de ucranianos, russos e lituanos, desde a adolescência escreve textos de ficção publicando-os em suplementos literários e revistas destinadas ao público infantil e juvenil, seu primeiro livro lançado foi "crescer é perigoso" em 1986 e é autora de romances e contos dentre eles "Gringa" o qual utilizaremos para fazer a nossa análise.

O conto "Gringa" tem como personagem principal Sorá que é uma imigrante brasileira que mora na Rússia e que vai à festa do seu noivado com Victor, que acontece na casa da avó dele e em meio à festa ela acaba por descobrir que as pessoas que lá estão não gostam muito de imigrantes, porém isso não fica claro a não ser pelo modo como as pessoas demonstram por gestos e olhares e cochichos em russo. 
No conto que estamos analisando há um tema central que é percebido, a imigração e, mais especificamente, o preconceito que estes sofrem em terras estrangeiras, tudo isso provocado pelas diferenças que ambas apresentam, pois o conto começa por mostrar logo de início a diferença de Sorá em relação aos outros personagens.

Eu era a mais bonita, ali. Isso eu procurava repetir dentro de minha cabeça, minuto a minuto: a mais bonita. Mas talvez, naquela família, o que menos importava era beleza. Pior: a beleza seria um problema a mais para enfrentar. Eram gordas, as convidadas. A anfitriã também com sua óbvia dentadura de dentes certos demais. A avó usava uma peruca aloirada. O esmalte das primas era gritante, fora de moda. Ah, como eu conseguia maldosamente reparar nesses detalhes. E como me sentia infeliz, sabendo que era diferente deles... superior? Isso, nunca (KUPSTAS, 2002, p. 33).

Percebemos no trecho acima que Sorá observa a sua diferença em relação aos outros que estão na casa ao mostrar a sua beleza que é segundo ela mesma, muito maior que as das outras mulheres que lá estão, mas como a própria personagem fala isso seria um problema a mais, pois por mais que fosse mais bonita, ela se faz um questionamento se seria superior, já que uma imigrante que está em busca de um casamento e não fica claro o seu objetivo de estar naquelas terras, mas como a maioria é por necessidades econômicas, nunca seria superior a ninguém, já que por ser diferente pode demonstrar uma inferioridade e suas palavras podem revelar uma tentativa de afirmação para sua autoestima.

\footnotetext{
Victor não me deixava sozinha. Nós dois juntos, conduzidos para o melhor sofá da sala, sentados juntos, como "dois namoradinhos", falou sua tia, nos indicando o sofá estreito. E nós ficamos lá, quase sós, em meio à festa. Estavam sendo gentis: polidez enjoativa, sorriso educado; beijinhos da avó, resmungando palavras estrangeiras com Victor. Ele ficou corado, respondeu a avó. Meu Victor sempre tão fácil de corar. E tão ruim como mentiroso, quando perguntei o que a velhinha havia dito. Estávamos sós (KUPSTAS, 2002. p. 34).
}

Percebemos neste trecho o início da revelação do preconceito, mas não é preconceito escancarado, mas velado e de maneira quase imperceptível, pois o tratamento que davam a ela era de forma exagerada e que a própria personagem revela como enjoativo, mas ao mesmo tempo são pronunciadas palavras que ela compreendeu, mas o rosto de seu noivo revela a força das palavras, que faz com ela perceba a vergonha sofrida por ele, sendo que ele não revela o que foi pronunciado por tamanha gravidade e preconceito que talvez estejam contidos na frase.

À minha volta, gente falando em Russo, gente bebendo e me olhando; na sala, as senhoras e crianças. Um ou outro jovem, e nós. E daí que falassem em russo? Poderia ser alemão, polaco, grego. Eu continuaria sendo diferente. Sendo a brasileira gringa (KUPSTAS, 2002. p. 34). 
Novamente a personagem se vê como diferente e um dos elementos dessas diferenças é a língua, já que todos falavam em russo, e ela afirma que mesmo que fossem outras línguas, ela sempre seria considerada diferente, pois era de outra nacionalidade e nunca pertenceria a casa, à família, à nação. Conforme argumenta Roberto Damatta (1986, p. 18) “por ser um espaço assim inclusivo e, simultaneamente, exclusivo, a casa pode ter também seus agregados. Pessoas que vivem no domicílio, mas que não são parte da família."

Pedi licença para ir ao banheiro. Victor mal se moveu, eu ocupava tão pouco espaço na poltrona. Meus quadris estreitos, meu corpo magro. Eu não incomodava, era tão opaca, ou ao contrário? Exatamente por isso, era aquela com quem Victor não deveria casar. O grande erro, na família (KUPSTAS, 2002, p. 34).

As diferenças são mais que elementos que singularizam o ser, pois o que percebemos é que no caso do imigrante isso é utilizado como elemento para repudiar, levá-lo à margem, se sentir de uma forma ou outra não pertencente àquele lugar. Para o imigrante viver em outro lugar que não o seu, é depender da aceitação, mas essa é medida muitas vezes pela necessidade das sociedades de acolhimento em tê-los apenas para construção de uma mão de obra, produzindo assim uma subalternidade.

Da mesma maneira, a constante associação da imigração a um "problema" para a sociedade de acolhimento, um problema que cabe aos governos resolver, deixando entrar e permanecer apenas o número estritamente necessário para desempenhar as tarefas para os quais não há mão de obra disponível, essa associação não pode deixar de investir a figura do imigrante de um valor de "indesejabilidade", como se tratasse de um convidado indesejado, ou apenas tolerado à mesa como um ocidente cuja riqueza ajudou a construir, ontem como trabalhador indígena no sistema de exploração colonial, hoje como trabalhador imigrante na metrópole (DIAS, 2012, p. 24).

Como nos apresenta Dias (2012), o imigrante é apenas alguém que está na sociedade porque é de alguma forma útil, mas essa utilidade não é motivo de aceitação é apenas certa tolerância, para que a sua força de trabalho seja utilizada. No texto isso não fica claro, mas quando a personagem é apresentada à família e Victor procura deixar claro a formação dela e a classe econômica a qual pertence, é uma maneira de mostrar que pode ser útil, e pode ser utilizada como mão de obra.

Essa é a Sorá. Ela faz faculdade, vai ser pedagoga..., palavras ditas com pressa, muita pressa, antes que as pessoas pudessem terminar o que estavam pensando, (...) Ela é classe média, é inteligente. É igual a nós não é uma qualquer (KUPSTAS,2002, p.35). 
Mas fica evidente que Sorá não era bem vinda naquela casa, pois era uma brasileira e por ser dessa nacionalidade acaba por carregar consigo uma ideia de que brasileira é "puta", pela forma como se veste, isso é percebido no seguinte trecho:

- Josef, deixa a moça! Não repara, que o Josef... - a mãe de Victor chegou, fazendo um gesto, "meio alto", e resmungou em russo com ele, aquela língua que virava um código: falar mal de mim? Ou era medo, o medo da minha sedução - já levou o filho, quer o quê? Conquistar o pai? ( KUPSTAS, 2002, p. 35).

Apesar da personagem se encontrar em outra terra, acaba por carregar consigo o peso de seu país de origem e a identidade, pois para Bonnemaison e Cambrèzy (1996, p.10 apud HAESBAERT, 2005, p. 36) "o território cultural precede o território político e com mais razão precede o espaço econômico", quer dizer que nossas marcas culturais sempre estarão conosco, como algo que nos marca fora de nosso território é o que percebemos em mais um questionamento que Sorá se faz:

Eu devia estar maluca, eu exagerava. Isso é ridículo, Sorá. Acalme-se. Mas ainda ardiam na minha pele, meu coração, tantas outras marcas. "O Brasil é uma democracia racial”, nós aprendíamos na escola, desde o Jardim da Infância. E o primeiro xingamento que amiguinhas brancas me faziam era "preta", como se isso, sim, doesse mais que xingar mãe ou ofender honra (KUPSTAS, 2002, p. 35)

Essa diferença que a personagem traz consigo, irá se tornar bem mais forte, saindo de uma pequena diferença para um preconceito que está sentindo, pois suas características são bem mais marcantes em meio aos russos, já que eles são brancos, loiros de olhos azuis e talvez por esse motivo e por trazer consigo marcas de preconceitos em sua vida, vai passar pelo mesmo sentimento. "Preta, preta. Claro, eu era a única preta na festa. Victor abriu-me espaço no sofá” (KUPSTAS, 2002, p. 35).

A diferença acaba por se tornar um preconceito, pois ela se sente a única que atrai os olhares de quem está na festa mesmo fazendo as mesmas coisas que os outros fazem, é o peso de quem é um imigrante, alguém que não é desejado, que não é bem-vindo naquele lugar.

Florestan (1972, p. 73) argumenta que sociologicamente, o preconceito e a discriminação de cor são uma causa estrutural e dinâmica da "perpetuação do passado no presente", que seus efeitos normais e indiretos das funções do preconceito e da discriminação de cor é que o fazem, restringindo as oportunidades econômicas, educacionais, sociais e políticas do negro e do mulato, mantendo-os "fora do sistema" ou a margem e na periferia da ordem social competitiva. Vejamos o comportamento da personagem a seguir: 
Novos drinques, peguei meu terceiro copo. Todo mundo bebia lá que era um exagero, mas tinha certeza de que tia Wanda ou a avó contavam os meus drinques: brasileiro que bebe. Que fede. Preto. Prostituta. Ladrão. Ele podia escolher tanta moça, e justo uma preta que não presta. Os olhos deles falavam. Não podia ser só a minha imaginação; eu não seria tão louca assim; não seria (KUPSTAS, 2002. p. 36).

Como a narrativa é marcada pelo tempo psicológico, a estória acontece na mente de Sorá, por isso acredita estar louca com todos os pensamentos em relação aos outros que ali estavam e o modo que eles a enxergavam porque poderia ser algo apenas da sua cabeça e que realmente não seria uma indesejada naquele lugar, porém a personagem vai ficar com a certeza a partir do momento em que as sobrinhas de Victor entram em cena.

As sobrinhas (cinco e sete anos) com a outra ingenuidade: "Essa é a sua noiva, titio?" o eeeeeeessa soando como chicote, o risinho muito adulto, enquanto a mãe puxava as meninas pela mão, carregando depressa as autoras do crime de falarem alto o que todos pensavam. Todos (KUPSTAS, 2002, p. 36)

O que a personagem achava que era apenas algo em sua mente acaba de ser revelado pelas crianças, que o ser diferente realmente motivava o preconceito e ser uma imigrante preta, brasileira era sim um motivo para não estar ali, que necessitava sair, buscar o seu lugar, pois demonstravam que não era bem-vinda.

Por fim, a personagem acaba por aceitar de maneira submissa todos aqueles preconceitos velados que a família de Victor sentia por ela, pois por mais que revelasse o que estava sentindo, seus sentimentos não seriam de maneira nenhuma levados em conta e como Sorá mesmo fala seria considerada uma louca, pois a voz de quem não tem pertencimento não é ouvida, mas se faz de um silenciamento.

Desta vez, não me importei que duas lágrimas ultrapassassem os cílios - talvez também me chamassem de louca. Se comentasse meus sentimentos com meu noivo... bem. No "mas nós não a tratamos tão bem? vai-se entender o que passa pela cabeça dos pretos" (KUPSTAS, 2002, p. 37).

A personagem termina sua saga como uma imigrante onde na terra dos outros deve baixar a cabeça e se submeter aos preconceitos que lhes são colocados, pois não pode fazer nada que lhes faça pensar que é mais diferente em termos culturais, pois com certeza sofrerá mais preconceitos. 


\section{CONSIDERAÇÕES FINAIS}

O trabalho foi feito a partir de uma análise no conto "Gringa" nos discursos das personagens presentes na narrativa ficcional, a forma como o preconceito e a diferença se desenvolveram, demonstrando um certo temor de nacionalidade, tanto em quem é de fora, em especial a protagonista, quanto para o país acolhedor, como uma forma de compreender se existe um limite em ser diferente, pois o que mostrou a análise é que a diferença para quem é um imigrante é um motivo para gerar preconceito, já que este é visto como alguém que está ali como um intruso, como aquele que não faz parte, por não ter nascido naquela terra.

Percebemos ainda a existência dos preconceitos estarem ligados às marcas culturais que todos nós carregamos e que fazem a nossa identidade. Algo que nos chamou atenção é que muitos indivíduos, mesmo não sendo imigrantes, podem se identificar com a personagem, por trazer questões sociais bem marcantes com relação ao preconceito que não apenas centraliza a questão do imigrante, mas outros fatores de inferioridade quando se diz respeito ao diferente que pode ocorrer sobre questões de choques culturais entre regiões locais e familiares.

Outra visão é como tratamos ao longo do tempo o estrangeiro, o imigrante, como é o nosso comportamento diante da realidade com o diferente. Não percebendo que a forma que tratamos o outro diante de sua nacionalidade, pode ser uma ameaça, criando conflitos internos ao indivíduo se for de uma forma negativa.

Por meio dessa análise literária, foi percebido que muito mais do que um instrumento de prazer estético a arte pode ser um grande aliado na compreensão da sociedade, já que esta é produto do meio e, sendo assim, reflete as nossas ações boas ou ruins que constituem a nossa cultura.

O presente artigo também trouxe questões sobre o multiculturalismo, sobre o surgimento de grupos étnicos que nascem de processos migratórios e que o que antes era nacional passou a ser mais regional, ficou mais localizado.

Sobre os países que foram mais flexíveis as novas culturas, se desenvolveram mais que os outros, mas o Brasil se destaca no que se diz respeito à mistura das raças, culturas, como: arte, música, culinária, e nas características fisiológicas, onde somos sujeitos híbridos, não existe nada puro, somos uma mistura de etnias, costumes, uma diversidade cultural e rica e uma identidade que está sempre em processo de construção.

É importante destacar a importância da literatura para os estudos culturais, como forma de conhecimento que está atrelada ao mundo, à sociedade, às diferentes questões que 
abarcam uma nação e que servem como um instrumento de compreensão dessas questões como no caso aqui apresentado, o preconceito sofrido pelos imigrantes.

\section{REFERÊNCIAS}

BURKE, Peter. Hibridismo Cultural. São Leopoldo, Rs: Editora Usininos, 2003.

COSER, Stelamaris. Híbrido, Hibridismo e Hibridização. Conceitos de Literatura e Cultura/Eurídice Figueiredo, (org.)Juiz de Fora.UFJF, 2005.

DAMATTA, Roberto. O que faz o brasil, Brasil?.Rio de Janeiro: Rocco, 1986.

ECO, Humberto. Cincos escritos morais. Eliana Aguiar (Trad.), $7^{\mathrm{a}}$ ed. RJ, Record, 2006.

FIGUEIREDO, Eurídice (Org). Conceitos de literatura e Cultura. Juiz de Fora, UFJF, 2005.

FLORESTAN, Fernandes. O negro no mundo dos brancos. São Paulo: Difusão europeia do livro, 1972.

NETO, Arnaldo Rosa Vianna. Multiculturalismo e Pluriculturalismo. Conceitos de Literatura e Cultura/Eurídice Figueiredo, (org.)Juiz de Fora.UFJF, 2005.

HALL, Stuart. A identidade cultural na pós-modernidade. Trad. Tomaz da Silva e Guaciara Louro. Rio de Janeiro: DP\&A, 1997.

KUPSTAS, Márcia. Gringa In: Pátria Estranha - Histórias de peregrinação e sonho. São Paulo: Nova Alexandria, 2002.

SAYAD, Abdelmalek. A imigração: ou os paradoxos da alteridade. Tradução Cristina Murachco. São Paulo: EDUSP, 1998. 